\title{
A New Group Decision Model Based on Grey-Intuitionistic Fuzzy-ELECTRE and VIKOR for Contractor Assessment Problem
}

\author{
Hassan Hashemi ${ }^{1}$, Seyed Meysam Mousavi ${ }^{2}$, Edmundas Kazimieras Zavadskas ${ }^{3, *(1)}$, \\ Alireza Chalekaee ${ }^{3,4}$ and Zenonas Turskis ${ }^{3}$ \\ 1 Young Researchers and Elite Club, South Tehran Branch, Islamic Azad University, Tehran 1584743311, Iran; \\ hashemi.h@live.com \\ 2 Department of Industrial Engineering, Faculty of Engineering, Shahed University, Tehran 3319118651, Iran; \\ sm.mousavi@shahed.ac.ir \\ 3 Institute of Sustainable Construction, Faculty of Civil Engineering, Vilnius Gediminas Technical University, \\ Saulètekio ave. 11, LT-10223 Vilnius, Lithuania; zenonas.turskis@vgtu.lt \\ 4 School of Civil Engineering, Iran University of Science and Technology, Tehran 1684613114, Iran; \\ a_chalekaee@civileng.iust.ac.ir \\ * Correspondence: edmundas.zavadskas@vgtu.lt; Tel.: +370-5274-4910
}

Received: 18 April 2018; Accepted: 16 May 2018; Published: 18 May 2018

\begin{abstract}
This study introduces a new decision model with multi-criteria analysis by a group of decision makers (DMs) with intuitionistic fuzzy sets (IFSs). The presented model depends on a new integration of IFSs theory, ELECTRE and VIKOR along with grey relational analysis (GRA). To portray uncertain real-life situations and take account of complex decision problem, multi-criteria group decision-making (MCGDM) model by totally unknown importance are introduced with IF-setting. Hence, a weighting method depended on Entropy and IFSs, is developed to present the weights of DMs and evaluation factors. A new ranking approach is provided for prioritizing the alternatives. To indicate the applicability of the presented new decision model, an industrial application for assessing contractors in the construction industry is given and discussed from the recent literature.
\end{abstract}

Keywords: multi-criteria group decision-making; ELECTRE; VIKOR; IFSs; GRA; contractor assessment problem

\section{Introduction}

The contractor selection process (CSP) includes five main stages in practice as follows [1]:

- Project packaging;

- Invitation;

- Prequalification;

- Shortlisting;

- Bid evaluation.

Multi-criteria decision-making (MCDM) approach can be suitable in solving complex problems, such as executing system selection and contractor evaluation [2-4]. The CSP can be taken in the MCDM framework, considering an overall strategy [5-7]. Different criteria must be considered along with the interest of a group of experts or decision makers (DMs) [8]. For the CSP, analytical methods have not properly improved, despite a high increase in the multifaceted nature of projects along with a relative increase in candidate forms of executing systems for the projects. Hence, these decision tools and methods should be highlighted and employed [9]. 
The outranking methods, as an uncommon category of MCDM methods, meet the particular requirements of the soft decisions which properly handle the real-decision situations e.g., [10-13]. To start with outranking method, ELECTRE (ELimination and Choice Expressing the Reality) was created by Roy [14]. Some outranking approaches, based on ELECTRE as well-known model, were reported in recent years i.e., [15,16]. Hashemi et al. [17] utilized the interval-valued intuitionistic fuzzy (IVF)-ELECTRE III as a suitable choice, keeping in mind the end goal to illuminate an investment project selection problem. Azadnia et al. [18] used the fuzzy C-Means (FCM) clustering regarded as a data-mining approach to categorize suppliers, and ELECTRE has been utilized to rank the suppliers. Sevkli [19] compared and contrasted crisp and fuzzy ELECTRE approaches for the supplier evaluation in an industry case. Teixeira de Almeida [20] proposed a model that integrated ELECTRE and utility function regarding to outsourcing contracts appraisement. Montazer et al. [21] developed a fuzzy expert system that was utilized to assist firms with fuzzy ELECTRE III. Marzouk [22] regarded MCDM approach with ELECTRE III for the CSP. You et al. [23] extended MCDM approach based on ELECTRE III and best-worst techniques with the multiplicative preference relations and intuitionistic fuzzy sets (IFSs).

Classical MCDM methods assume that the ratings of alternatives and the evaluation factors' relative importance regarded ascertain numbers, but in real engineering applications and management situations, these assumptions are not practical [24]. Therefore, various types of membership functions by concentrating on ambiguous components have been applied in solving engineering and management problems [25-30]. The IFSs propose a generalization of fuzzy sets theory [31,32]. Recently, this theory regards the explicit presentation and expression with both likes and dislikes. Various scientists have displayed new approaches and methodologies to adapt to the fuzzy MCDM (FMCDM) issues with taking IFSs. Chen [33] developed an IFS-approach to the problem solving, by utilizing decision tree induction. Ye [34] regarded decision problems by unknown information on weights of criteria with Entropy and IFSs. Li et al. [35] provided a linear programming approach for handling the MCDM with DMs and IFSs. Liu [36] extended power-average operator with IFSs for dealing with the MCDM. Fouladgar et al. [37] proposed a model to regard a specific end goal to figure the importance weights of assessment components and to rank feasible projects, respectively. Hashemi et al. [38] developed a compromise ratio approach with IFSs theory to water resources area. Zhao et al. [39] reported an IFS-VIKOR method to handle the supplier selection. Hosseinzadeh et al. [40] designed an MCDM model with a combination of IFS, grey relational analysis (GRA) and TOPSIS method to select the best precursor. Zavadskas et al. [41] extended the MULTIMOORA approach with IVIFSs for analyzing real-world civil engineering problems. Keshavaraz Ghorabaee et al. [42] reported the compromise solution by T2FSs for project selection problem.

This study designs a new multi-criteria group decision-making (MCGDM) model in light of novel hybrid approaches of the GRA, IF-ELECTRE and VIKOR along with multi-criteria analysis. In the IF-ELECTRE method, the calculation process of concordance dominance (CD) and discordance dominance (DD) matrixes are in light of the idea that the potential candidate or alternative ought to have the most limited distance from the positive ideal solution (PIS) and farthest distance from the negative ideal solution (NIS). Further, a weighting approach is regarded and extended in view of a generalized version of the Entropy and IFSs to determine weights of both DMs and the criteria. Finally, in view of the idea of the VIKOR method, a new index is introduced for appraising the alternatives.

The rest of this study is arranged as follows. An overview of IFSs is reported in Section 2. A decision model is illustrated in Section 3. A real application example is presented for the contractor selection problem according to the literature in Section 4 to indicate the steps of the model. In the final section, conclusions will be given. 


\section{Preliminaries}

Atanassov [31] developed traditional fuzzy set to the IFS with regard to a hesitation degree. An IF is defined as:

$$
I=\left\{\chi, \mu_{I}(\chi), v_{I}(\chi) \mid \chi \in \mathrm{X}\right\},
$$

which is described with a membership function $\mu_{I}$ and a non-membership function $v_{I}$, where

$$
\begin{aligned}
& \mu_{I}: \chi \rightarrow[0,1], \chi \in X \rightarrow \mu_{A}(\chi) \in[0,1], \\
& v_{I}: \chi \rightarrow[0,1], \chi \in X \rightarrow v_{A}(\chi) \in[0,1]
\end{aligned}
$$

with the condition

$$
0 \leq \mu_{I}(\chi)+v_{I}(\chi) \leq 1 \text { for all } \chi \in \mathrm{X}
$$

The third parameter of IFS is $\pi_{I}(\chi)$, regarded as the intuitionistic fuzzy index as below [43]:

$$
\pi_{I}(\chi)=1-\mu_{I}(\chi)-v_{I}(\chi) .
$$

and

$$
0 \leq \pi_{I}(\chi) \leq 1
$$

Definition $1[31,44]$. Let $I$ and $I^{\prime}$ be two IFSs, then

$$
\begin{aligned}
& I \bigoplus I^{\prime}=\left\{\chi, \mu_{I}(\chi)+v_{I^{\prime}}(\chi)-\mu_{I}(\chi) \cdot \mu_{I^{\prime}}(\chi), v_{I}(\chi) \cdot v_{I^{\prime}}(\chi) \mid \chi \in X\right\}, \\
& I \otimes I^{\prime}=\left\{\chi, \mu_{I}(\chi) \cdot \mu_{I^{\prime}}(\chi), v_{I}(\chi)+v_{I^{\prime}}(\chi)-v_{I}(\chi) \cdot v_{I^{\prime}}(\chi) \mid \chi \in X\right\} .
\end{aligned}
$$

From these Equations, the following relations are obtained:

$$
\begin{aligned}
& n I=\left\{\chi,\left(1-\left(1-\mu_{I}(\chi)\right)^{n},\left(v_{I}(\chi)\right)^{n} \mid \chi \in X\right\}, n \geq 0,\right. \\
& I^{n}=\left\{\chi,\left(\mu_{I}(\chi)\right)^{n},\left(1-\left(1-v_{I}(\chi)\right)^{n}, \mid \chi \in X\right\}, n \geq 0 .\right.
\end{aligned}
$$

Definitionn $2[45,46]$. Let $I$ be an IFS. Then the score function $S$ and the accuracy function $H$ may be represented as below:

$$
S(I)=\mu_{I}-v_{I},
$$

and

$$
H(I)=\mu_{I}-v_{I},
$$

respectively. Clearly $S(I) \in[-1,1]$ and $H(I) \in[0,1]$ for any IFS $I$.

Definitionn 3 [47]. Intuitionistic fuzzy weighted geometric with respect to a weighting vector $\omega$, $I F W G_{\omega}$ is characterized as

$$
\operatorname{IFWG} G_{\omega}\left(I_{1}, I_{2}, \ldots, I_{n}\right)=\prod_{j=1}^{n} I_{j}^{\omega_{j}}=\left\langle\prod_{j=1}^{n}\left(\mu_{I_{j}}\right)^{\omega_{j}}, 1-\prod_{j=1}^{n}\left(1-v_{I j}\right)^{\omega_{j}}\right\rangle,
$$

where $\omega_{k} \in[0,1]$, and $\sum_{j=1}^{n} \omega_{j}=1,(j=1,2, \ldots, n)$. 
Definitionn 4 [48]. Distance between two IFSs $I$ and $I^{\prime}$ can be characterized as takes after:

$$
D\left(I, I^{\prime}\right)=\sqrt{\frac{1}{2 n} \sum_{j=1}^{n}\left[\left(\mu_{I}\left(\chi_{j}\right)-\mu_{I^{\prime}}\left(\chi_{j}\right)\right)^{2}+\left(v_{I}\left(\chi_{j}\right)-v_{I^{\prime}}\left(\chi_{j}\right)\right)^{2}+\left(\pi_{I}\left(\chi_{j}\right)-\pi_{I^{\prime}}\left(\chi_{j}\right)\right)^{2}\right]}
$$

\section{Proposed Uncertain Group Decision Model}

For the MCGDM problem with IF uncertainty, let $C A=\left\{C A_{1}, C A_{2}, \ldots, C A_{\mathrm{m}}\right\}$ be a set of $m$ candidates or alternatives, and $C R=\left\{C R_{1}, C R_{2}, \ldots, C R_{\mathrm{n}}\right\}$ be the set of $n$ conflicting criteria, and let $D M=\left\{D M_{1}, D M_{2}, \ldots, D M_{t}\right\}$ be a set of $t$ DMs. Let $X^{(e)}=\left(\widetilde{x}_{i j}^{(e)}\right)_{m \times n}$ be an IF-decision matrix, where $\widetilde{x}_{i j}^{(e)}=\left(\mu_{i j}^{(e)}, v_{i j}^{(e)}, \pi_{i j}^{(e)}\right)$ is a criterion value provided by eth DM, denoted by an IFN, for the alternative $C A_{i}$ versus the criterion $C R_{j}$.

The process of the proposed group decision model based on GRA, IF-ELECTRE and VIKOR methods are provided as below.

\subsection{Determine the DMs' Importance, Criteria' Weights and Aggregated IFS Decision Matrix}

There are various tools and approaches to regard the criteria' weights. This study adopts information regarding Entropy method to provide criteria' weights. The Entropy was one of the ideas in thermodynamics originally by Shannon [49]. The steps of determining the DMs' importance and criteria' weights by Entropy method are reported as below:

(1) To denote the DMs' importance from the IF-decision matrix, the method of Entropy weights [50] is given by:

$$
\lambda_{i j}^{(e)}=\frac{1-J_{i j}^{(e)}}{t-\sum_{k=1}^{t} J_{i j}^{(e)}},
$$

where $\lambda_{i j}^{(e)} \in[0,1], \sum_{e=1}^{t} \lambda_{i j}^{(e)}=1, i=1,2, \ldots, m, j=1,2, \ldots, n, e=1,2, \ldots, t$ and $J_{i j}^{(e)}$ is computed by:

$$
J_{i j}^{(e)}=\frac{1}{\sqrt{2}-1} \times\left\{\sin \frac{\pi\left(1+\mu_{i j}^{(e)}-v_{i j}^{(e)}\right)}{4}+\sin \frac{\pi\left(1-\mu_{i j}^{(e)}+v_{i j}^{(e)}\right)}{4}-1\right\},
$$

where $0 \leq J_{i j}^{(e)} \leq 1, i=1,2, \ldots, m, j=1,2, \ldots, n$ and $e=1,2, \ldots, t$.

(2) After weights' values for the DMs are obtained, the evaluating values described by different DMs are aggregated regarding the IFWG operator by:

$$
\begin{gathered}
\widetilde{r}_{i j}=\left(\widetilde{x}_{i j}^{(1)}\right)^{\lambda_{i j}^{(1)}} \otimes\left(\widetilde{x}_{i j}^{(2)}\right)^{\lambda_{i j}^{(2)}} \otimes \ldots \otimes\left(\widetilde{x}_{i j}^{(t)}\right)^{\lambda_{i j}^{(t)}}, \\
\widetilde{r}_{i j}=\left\langle\mu_{i j}, v_{i j}\right\rangle=\left\langle\prod_{e=1}^{t}\left(\mu_{i j}^{(e)}\right)^{\lambda_{i j}^{(e)}}, 1-\prod_{e=1}^{t}\left(1-v_{i j}^{(e)}\right)^{\lambda_{i j}^{(e)}}\right\rangle .
\end{gathered}
$$

(3) To provide $w_{j}$ as weights of evaluation criteria, IF-Entropy is as below [50]:

$$
G_{j}=\frac{1}{m} \sum_{i=1}^{m} \frac{1}{\sqrt{2}-1}\left(\sin \frac{\pi\left(1+\mu_{i j}-v_{i j}\right)}{4}+\sin \frac{\pi\left(1-\mu_{i j}+v_{i j}\right)}{4}-1\right),
$$

where $0 \leq G_{j} \leq 1, i=1,2, \ldots, m$ and $j=1,2, \ldots, n$. 
Entropy weight of the $j$ th criterion is reported as:

$$
w_{j}=\frac{1-G_{j}}{n-\sum_{j=1}^{n} G_{j}},
$$

where $w_{j} \in[0,1], \sum_{j=1}^{n} w_{j}=1, j=1,2, \ldots, n$.

\subsection{Ranking of Alternatives by the Model}

We can consider different alternatives and compare based on their IF values. Various types of concordance sets as the concordance set, midrange concordance set, and weak concordance set (CS) by ideas of score function and accuracy function are classified. It is also similar to discordance set (DS) [13].

Let $\widetilde{X}=\left(\mu_{\widetilde{x}}, v_{\widetilde{x}}, \pi_{\widetilde{x}}\right)$ be an IF value. The CS $C_{k l}$ of $A_{k}$ and $A_{l}$ contains all criteria for which $A_{k}$ is preferred to $A_{l}$. We apply ideas of score function, accuracy function, and hesitancy degree of the IFNs to classify concordance sets. The $\mathrm{CS}_{k l}$ can be provided as follows [13]:

$$
C_{k l}^{1}=\left\{j \mid \mu_{k j}>\mu_{l j}, v_{k j}<v_{l j} \text { and }\left(\mu_{k j}+v_{k j}\right)>\left(\mu_{l j}+v_{l j}\right)\right\}
$$

where $j=1,2, \ldots, n$, and Equation (21) can be more concordant than Equation (22) or Equation (23).

The midrange $\mathrm{CS} C_{k l}^{2}$ is denoted:

$$
C_{k l}^{2}=\left\{j \mid \mu_{k j}>\mu_{l j}, v_{k j}<v_{l j} \text { and }\left(\mu_{k j}+v_{k j}\right) \leq\left(\mu_{l j}+v_{l j}\right)\right\}
$$

The main difference between Equations (21) and (22) is the hesitancy degree; it at the $k$ th alternative versus the $j$ th criterion is regarded higher than the $l$ th alternative versus the jth criterion in the midrange concordance set. Thus, Equation (21) can be more concordant than (22).

The weak $\mathrm{CS}_{k l}^{3}$ is denoted as:

$$
C_{k l}^{3}=\left\{j \mid \mu_{k j} \geq \mu_{l j} \text { and } v_{k j} \geq v_{l j}\right\}
$$

The degree of non-membership at the $k$ th alternative versus the $j$ th criterion is regarded higher than the $l$ th alternative versus the $j$ th criterion in weak concordance set; thus, Equation (22) can be more concordant than (23).

The DS includes all criteria for which $A_{k}$ is not related to $A_{l}$ by:

$$
D_{k l}^{1}=\left\{j \mid \mu_{k j}<\mu_{l j}, v_{k j} \geq v_{l j} \text { and }\left(\mu_{k j}+v_{k j}\right) \leq\left(\mu_{l j}+v_{l j}\right)\right\}
$$

The midrange DS $D_{k l}^{2}$ is denoted as follows:

$$
D_{k l}^{2}=\left\{j \mid \mu_{k j}\left\langle\mu_{l j}, v_{k j}\right\rangle v_{l j} \text { and }\left(\mu_{k j}+v_{k j}\right)>\left(\mu_{l j}+v_{l j}\right)\right\}
$$

Equation (24) can be more discordant than Equation (25).

The weak DS $D_{k l}^{3}$ is denoted as follows:

$$
D_{k l}^{3}=\left\{j \mid \mu_{k j}<\mu_{l j} \text { and } v_{k j}<v_{l j}\right\}
$$

Equation (25) can be more discordant than Equation (26). 
In the proposed new hybrid GRA, IF-ELECTRE and VIKOR model with assessment data, the relative value of CS could be taken through the concordance index. Hence, the concordance index $C_{k l}$ between $A_{k}$ and $A_{l}$ in this study is characterized as:

$$
\varphi_{k l}=w_{c^{1}} \times \sum_{j \in C_{k l}^{1}} w_{j}+w_{c^{2}} \times \sum_{j \in C_{k l}^{2}} w_{j}+w_{c^{3}} \times \sum_{j \in C_{k l}^{3}} w_{j}
$$

where $w_{c^{1}}, w_{c^{2}}$ and $w_{c^{3}}$ are the weights of the concordance, midrange concordance, and weak concordance sets, respectively, and $w_{j}$ is the weight of the evaluation criteria.

Concordance matrix $\Phi$ could be formed as:

$$
\Phi=\left[\begin{array}{ccccc}
- & \varphi_{12} & \varphi_{13} & \ldots & \varphi_{1 m} \\
\varphi_{21} & - & \varphi_{23} & \ldots & \varphi_{2 m} \\
\vdots & \vdots & - & \ddots & \vdots \\
\varphi_{(m-1) 1} & \varphi_{(m-1) 2} & \ldots & - & \varphi_{(m-1) m} \\
\varphi_{m 1} & \varphi_{m 2} & \ldots & \varphi_{m(m-1)} & -
\end{array}\right]
$$

where the maximum and the minimum values of $\varphi_{k l}$ are denoted by $\varphi^{*}$ and, $\varphi^{-}$which are the positive ideal point and negative ideal point, respectively. Also, a higher value of $\varphi_{k l}$ indicates that $A_{k}$ would be preferred to $A_{l}$ and vice versa.

Evaluations of certain $A_{k}$ are worse than appraisements of a competing $A_{k}$. Discordance index is provided as:

$$
\varepsilon_{k l}=\frac{\max _{j \in D_{k l}} w_{D}^{*} \times d\left(\widetilde{x}_{k j}, \widetilde{x}_{l j}\right)}{\max _{j \in J} d\left(\widetilde{x}_{k j}, \widetilde{x}_{l j}\right)},
$$

where $d\left(\widetilde{x}_{k j}, \widetilde{x}_{l j}\right)$ is determined by Equation (14), and $w_{D}^{*}$ is equal to $w_{D^{1}}, w_{D^{2}}$ or $w_{D^{3}}$. Discordance matrix $\mathrm{E}$ is formed as:

$$
\mathrm{E}=\left[\begin{array}{ccccc}
- & \varepsilon_{12} & \varepsilon_{13} & \ldots & \varepsilon_{1 m} \\
\varepsilon_{21} & - & \varepsilon_{23} & \ldots & \varepsilon_{2 m} \\
\vdots & \vdots & - & \ddots & \vdots \\
\mathcal{\varepsilon}_{(m-1) 1} & \varepsilon_{(m-1) 2} & \ldots & - & \varepsilon_{(m-1) m} \\
\varepsilon_{m 1} & \varepsilon_{m 2} & \ldots & \varepsilon_{m(m-1)} & -
\end{array}\right]
$$

where the maximum and the minimum values of $\varepsilon_{k l}$ are indicated with $\varepsilon^{*}$ and $\varepsilon^{-}$, which are the negative ideal and positive ideal points, respectively. A higher value of $\varepsilon_{k l}$ indicates that $A_{k}$ would be less favourable than $A_{l}$ and vice versa.

Steps of the GRA algorithm can be reported as below [51-54]: The grey relational coefficient is calculated. The grey relational coefficient $\gamma\left(x_{0 j}, x_{i j}\right)$ is computed by:

$$
\gamma\left(x_{0 j}, x_{i j}\right)=\frac{\operatorname{minmin}_{i}\left|x_{0 j}-x_{i j}\right|+\rho \operatorname{maxmax}_{i}\left|x_{0 j}-x_{i j}\right|}{\left|x_{0 j}-x_{i j}\right|+\rho \max _{i} \max _{j}\left|x_{0 j}-x_{i j}\right|},
$$

where $\rho$ is the identification coefficient $\rho \in[0,1], i=1,2, \ldots, m$ and $j=1,2, \ldots, n$.

The grade $\gamma\left(x_{0 j}, x_{i j}\right)$ between $x_{0}$ and $x_{i}$ can be as:

$$
\gamma\left(x_{0}, x_{i}\right)=\sum_{j=1}^{n} w_{j} \gamma\left(x_{0 j}, x_{i j}\right) \text { and } \sum_{j=1}^{n} w_{j}=1
$$


Introduced CD matrix calculation process in this study is according to the compromise solution idea. It means that the alternative must have the shortest grey relational coefficient from PIS and the farthest grey relational coefficient from the NIS; thus, the CD matrix $\Psi$ is formed as:

$$
\Psi=\left[\begin{array}{ccccc}
- & \psi_{12} & \psi_{13} & \ldots & \psi_{1 m} \\
\psi_{1 m} & - & p_{23} & \ldots & \psi_{2 m} \\
\vdots & \vdots & - & \ddots & \vdots \\
\psi_{(m-1) 1} & \psi_{(m-1) 2} & \ldots & - & \psi_{(m-1) m} \\
\psi_{m 1} & \psi_{m 2} & \ldots & \psi_{m(m-1)} & -
\end{array}\right]
$$

where

$$
\begin{gathered}
\psi_{k l}=\frac{\xi_{k l}^{+}}{\xi_{k l}^{-}+\xi_{k l}^{+}}, \\
\xi_{k l}^{+}=\frac{\min _{1 \leq k \leq m 1 \leq l \leq m} \min _{1}\left|\varphi^{*}-\varphi_{k l}\right|+\rho \max _{1 \leq k \leq m 1 \leq l \leq m} \max ^{*}-\varphi_{k l} \mid}{\left|\varphi^{*}-\varphi_{k l}\right|+\rho \max _{1 \leq k \leq m 1 \leq l \leq m}\left|\varphi^{*}-\varphi_{k l}\right|}, k \text { and } l=1,2, \ldots, m, \\
\xi_{k l}^{-}=\frac{\min _{1 \leq k \leq m 1 \leq l \leq m} \min \left|\varphi^{-}-\varphi_{k l}\right|+\rho \max _{1 \leq k \leq m 1 \leq l \leq m} \max \left|\varphi^{-}-\varphi_{k l}\right|}{\left|\varphi^{-}-\varphi_{k l}\right|+\rho \max _{1 \leq k \leq m 1 \leq l \leq m} \max ^{-}-\varphi_{k l} \mid}, k \text { and } l=1,2, \ldots, m .
\end{gathered}
$$

A higher value of $\psi_{k l}$ could indicate that $A_{k}$ is less favourable than $A_{l}$.

In a similar way, the presented DD matrix is formed in this study similar to the proposed CD matrix calculation process; thus, the DD matrix $\Omega$ is formed as:

$$
\Omega=\left[\begin{array}{ccccc}
- & \omega_{12} & \omega_{13} & \ldots & \omega_{1 m} \\
\omega_{1 m} & - & p_{23} & \ldots & \omega_{2 m} \\
\vdots & \vdots & - & \ddots & \vdots \\
\omega_{(m-1) 1} & \omega_{(m-1) 2} & \ldots & - & \omega_{(m-1) m} \\
\omega_{m 1} & \omega_{m 2} & \ldots & \omega_{m(m-1)} & -
\end{array}\right]
$$

where

$$
\begin{aligned}
& \omega_{k l}=\frac{\zeta_{k l}^{+}}{\zeta_{k l}^{-}+\zeta_{k l}^{+}}, \\
& \zeta_{k l}^{+}=\frac{\min _{1 \leq k \leq m 1 \leq l \leq m} \min _{1}\left|\varepsilon^{*}-\varepsilon_{k l}\right|+\rho \max _{1 \leq k \leq m} \max _{1 \leq l \leq m}\left|\varepsilon^{*}-\varepsilon_{k l}\right|}{\left|\varepsilon^{*}-\varepsilon_{k l}\right|+\rho \max _{1 \leq k \leq m 1 \leq l \leq m} \max ^{*}\left|\varepsilon_{k l}^{*}\right|}, k \text { and } l=1,2, \ldots, m \text {, } \\
& \zeta_{k l}^{-}=\frac{\min _{1 \leq k \leq m 1 \leq l \leq m} \min _{1}\left|\mathcal{\varepsilon}^{-}-\varepsilon_{k l}\right|+\rho \max _{1 \leq k \leq m 1 \leq l \leq m} \max ^{-\mathcal{E}^{-}-\varepsilon_{k l} \mid}}{\left|\mathcal{\varepsilon}^{-}-\varepsilon_{k l}\right|+\rho \max _{1 \leq k \leq m 1 \leq l \leq m} \max \left|\mathcal{E}^{-}-\varepsilon_{k l}\right|}, k \text { and } l=1,2, \ldots, m .
\end{aligned}
$$

A higher value of $\omega_{k l}$ could indicate that $A_{k}$ is preferred to $A_{l}$. According to the VIKOR method idea, the $\mathcal{I}_{i}, \mathcal{R}_{i}, \mathcal{I}_{i}^{\prime}$ and $\mathcal{R}_{i}^{\prime}$ values are represented by:

$$
\begin{aligned}
& \mathcal{I}_{i}=\sum_{l=1 ; l \neq k}^{m} \psi_{i l}, \\
& \mathcal{R}_{i}=\max _{l}\left(\psi_{i l}\right), \\
& \mathcal{I}_{i}^{\prime}=\sum_{l=1 ; l \neq k}^{m} \omega_{i l},
\end{aligned}
$$




$$
\mathcal{R}_{i}^{\prime}=\max _{l}\left(\omega_{i l}\right)
$$

Then, the values of indices $\delta_{i}$ and $\varrho_{i}$ are proposed:

$$
\delta_{i}=\left(\frac{\mathcal{I}_{i}+\mathcal{R}_{i}}{2}\right)\left(\frac{\mathcal{I}_{i}-\mathcal{I}^{+}}{\mathcal{I}^{-}-\mathcal{I}^{+}}\right)+\left(\frac{2-\left(\mathcal{I}_{i}+\mathcal{R}_{i}\right)}{2}\right)\left(\frac{\mathcal{R}_{i}-\mathcal{R}^{+}}{\mathcal{R}^{-}-\mathcal{R}^{+}}\right)
$$

and

$$
\varrho_{i}=\left(\frac{\mathcal{I}_{i}^{\prime}+\mathcal{R}_{i}^{\prime}}{2}\right)\left(\frac{\mathcal{I}_{i}^{\prime}-\mathcal{I}^{\prime-}}{\mathcal{I}^{\prime+}-\mathcal{I}^{\prime-}}\right)+\left(\frac{2-\left(\mathcal{I}_{i}^{\prime}+\mathcal{R}_{i}^{\prime}\right)}{2}\right)\left(\frac{\mathcal{R}_{i}^{\prime}-\mathcal{R}^{\prime-}}{\mathcal{R}^{\prime+}-\mathcal{R}^{\prime-}}\right),
$$

where $\left\{\begin{array}{l}\mathcal{I}^{+}=\min _{i} \mathcal{I}_{i} \\ \mathcal{I}^{-}=\max _{i} \mathcal{I}_{i}\end{array},\left\{\begin{array}{l}\mathcal{R}^{+}=\min _{i} \mathcal{R}_{i} \\ \mathcal{R}^{-}=\max _{i} \mathcal{R}_{i}\end{array},\left\{\begin{array}{l}\mathcal{I}^{\prime+}=\max _{i} \mathcal{I}_{i}^{\prime} \\ \mathcal{I}^{\prime-}=\min _{i} \mathcal{I}_{i}^{\prime}\end{array},\left\{\begin{array}{l}\mathcal{R}^{\prime+}=\max _{i} \mathcal{I}_{i} \\ \mathcal{R}^{\prime-}=\min _{i} \mathcal{I}_{i}\end{array}\right.\right.\right.\right.$.

We have the following relation:

$$
Q_{i}=\frac{\delta_{i}}{\delta_{i}+\varrho_{i}}
$$

$Q_{i}$ is the final value of assessment. All options can be positioned by $Q_{i}$. The best option $A^{*}$ can be characterized as below:

$$
A^{*}=\max \left\{Q_{i}\right\}
$$

\subsection{Algorithm}

An algorithm of the proposed decision model can be given as below:

step 1. A group of DMs is established to solve the complicated decision problem by considering conflicting criteria;

step 2. Proper criteria are reported for the selection problem;

step 3. Provide the ratings of each candidate versus each selected criterion for each DM;

step 4. Weight of each DM from the decision matrix is calculated by Equations (15) and (16);

step 5. Construct an aggregated IFS decision matrix by Equations (17) and (18);

step 6. Present the weights of appraisement criteria by Equations (19) and (20);

step 7. Identify the CS and DS. Find $C_{k l}^{1}, C_{k l}^{2}, C_{k l}^{3}, D_{k l}^{1}, D_{k l}^{2}$ and $D_{k l}^{3}$ for pair-wise comparisons of candidates by Equations (21)-(26);

step 8. Form the concordance matrix $\Phi$ by Equations (27) and (28);

step 9. Calculate the discordance matrix $E$ by Equations (29) and (30);

step 10. Form CD matrix $P$ by Equations (33)-(36);

step 11. Form DD matrix $O$ by Equations (37)-(40);

step 12. Determine the values of $\mathcal{I}_{i}, \mathcal{R}_{i}, \mathcal{I}_{i}^{\prime}$ and $\mathcal{R}_{i}^{\prime}$ by Equations (41)-(44);

step 13. Compute the values of indices $\delta_{i}$ and $\varrho_{i}$ are by Equations (45) and (46);

step 14. Calculate values of ranking index $\left(Q_{i}\right)$ using Equation (47). Rank the candidates in decreasing order.

Finally, a flowchart of the proposed model is illustrated in Figure 1. 


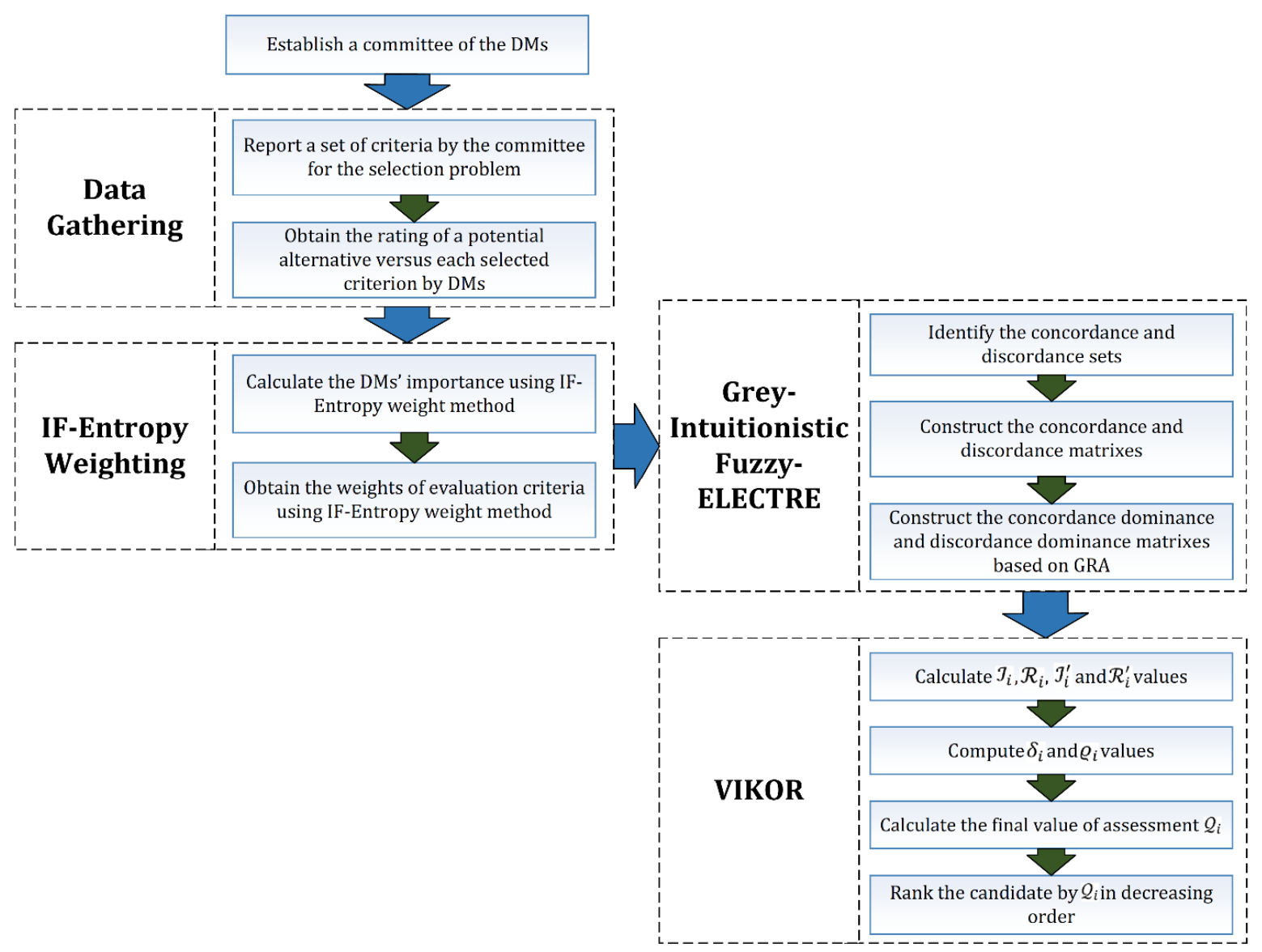

Figure 1. Flowchart of proposed model.

\section{Solution of Contractor Assessment Problem}

\subsection{Implementation and Computational Results}

Construction projects are initiated in dynamically changing and complicated environment, which result in circumstances of high uncertainty and risks [55,56]. Choosing the best alternative for a building is of great importance for owners, contractors, and stakeholders [57]. To exhibit the appropriateness of the soft decision model, a case study from the recent literature [58] is presented regarding the construction contractor assessment. This assessment can be via some conflicting criteria. A group of three $\mathrm{DMs}\left(D M_{1}, D M_{2}\right.$, and $\left.D M_{3}\right)$ is arranged to appraise the appropriate contractor. In this industrial application, five potential contractors $\left(\mathrm{CO}_{1}, \mathrm{CO}_{2}, \ldots, \mathrm{CO}_{5}\right)$ are chosen, and twenty criteria $\left(C R_{1}, C R_{2}, \ldots, C R_{20}\right)$. are reported for final assessments (steps 1 and 2). By taking DMs' judgments, all ratings of alternatives versus evaluation factors are represented with linguistic variables by Table 1 .

Table 1. Linguistic variables for performance ratings.

\begin{tabular}{cc}
\hline Linguistic Variables & Intuitionistic Fuzzy Numbers \\
\hline Verygood (VG) & $\langle 0.90,0.10\rangle$ \\
Good (G) & $\langle 0.80,0.15\rangle$ \\
Medium good (MG) & $\langle 0.65,0.25\rangle$ \\
Fair (F) & $\langle 0.50,0.40\rangle$ \\
Medium poor (MP) & $\langle 0.30,0.60\rangle$ \\
Poor (P) & $\langle 0.20,0.75\rangle$ \\
Verypoor (VP) & $\langle 0.10,0.90\rangle$ \\
\hline
\end{tabular}


The performance of alternatives in terms of appraisement criteria is represented by three DMs and then illustrated in Table 2 (step 3).

Table 2. Ratings of contractors.

\begin{tabular}{|c|c|c|c|c|}
\hline \multirow{2}{*}{ Criteria } & \multirow{2}{*}{ Contractors } & \multicolumn{3}{|c|}{ Decision Makers } \\
\hline & & $D M_{1}$ & $\mathrm{DM}_{2}$ & $\mathrm{DM}_{3}$ \\
\hline \multirow{5}{*}{$C R_{1}$} & $\mathrm{CO}_{1}$ & $F$ & $M P$ & $M P$ \\
\hline & $\mathrm{CO}_{2}$ & $G$ & $M G$ & $V G$ \\
\hline & $\mathrm{CO}_{3}$ & $M P$ & $F$ & $F$ \\
\hline & $\mathrm{CO}_{4}$ & $M G$ & G & $F$ \\
\hline & $\mathrm{CO}_{5}$ & $M G$ & $F$ & $F$ \\
\hline \multirow{5}{*}{$C R_{2}$} & $\mathrm{CO}_{1}$ & $F$ & $M P$ & $M P$ \\
\hline & $\mathrm{CO}_{2}$ & $V G$ & $G$ & $G$ \\
\hline & $\mathrm{CO}_{3}$ & $M G$ & G & $G$ \\
\hline & $\mathrm{CO}_{4}$ & G & $M G$ & $V G$ \\
\hline & $\mathrm{CO}_{5}$ & $M G$ & $F$ & $F$ \\
\hline \multirow{5}{*}{$C R_{3}$} & $\mathrm{CO}_{1}$ & $V G$ & $V G$ & $G$ \\
\hline & $\mathrm{CO}_{2}$ & $M G$ & $G$ & G \\
\hline & $\mathrm{CO}_{3}$ & G & $V G$ & $M G$ \\
\hline & $\mathrm{CO}_{4}$ & $M G$ & G & G \\
\hline & $\mathrm{CO}_{5}$ & $F$ & $M P$ & $M G$ \\
\hline \multirow{5}{*}{$C R_{4}$} & $\mathrm{CO}_{1}$ & $M P$ & $F$ & $F$ \\
\hline & $\mathrm{CO}_{2}$ & $G$ & $M G$ & $M G$ \\
\hline & $\mathrm{CO}_{3}$ & $F$ & $M P$ & $M G$ \\
\hline & $\mathrm{CO}_{4}$ & G & $V G$ & $M G$ \\
\hline & $\mathrm{CO}_{5}$ & $M G$ & $G$ & $F$ \\
\hline \multirow{5}{*}{$C R_{5}$} & $\mathrm{CO}_{1}$ & $F$ & $M G$ & $M P$ \\
\hline & $\mathrm{CO}_{2}$ & $V G$ & G & G \\
\hline & $\mathrm{CO}_{3}$ & $M G$ & $F$ & G \\
\hline & $\mathrm{CO}_{4}$ & $M G$ & $F$ & $G$ \\
\hline & $\mathrm{CO}_{5}$ & $M G$ & G & G \\
\hline \multirow{5}{*}{$C R_{6}$} & $\mathrm{CO}_{1}$ & $F$ & $M G$ & $M P$ \\
\hline & $\mathrm{CO}_{2}$ & $V G$ & $V G$ & $G$ \\
\hline & $\mathrm{CO}_{3}$ & $M G$ & $F$ & $F$ \\
\hline & $\mathrm{CO}_{4}$ & G & $V G$ & $M G$ \\
\hline & $\mathrm{CO}_{5}$ & $G$ & $V G$ & $M G$ \\
\hline \multirow{5}{*}{$C R_{7}$} & $\mathrm{CO}_{1}$ & $M G$ & $G$ & $G$ \\
\hline & $\mathrm{CO}_{2}$ & G & $M G$ & $V G$ \\
\hline & $\mathrm{CO}_{3}$ & $M G$ & $F$ & $F$ \\
\hline & $\mathrm{CO}_{4}$ & G & $M G$ & $V G$ \\
\hline & $\mathrm{CO}_{5}$ & G & $M G$ & $M G$ \\
\hline \multirow{5}{*}{$C R_{8}$} & $\mathrm{CO}_{1}$ & $F$ & $M G$ & $M P$ \\
\hline & $\mathrm{CO}_{2}$ & $M G$ & G & $G$ \\
\hline & $\mathrm{CO}_{3}$ & $F$ & $M G$ & $M G$ \\
\hline & $\mathrm{CO}_{4}$ & $M G$ & $F$ & $F$ \\
\hline & $\mathrm{CO}_{5}$ & $M G$ & $F$ & $F$ \\
\hline \multirow{5}{*}{$C R_{9}$} & $\mathrm{CO}_{1}$ & $M G$ & $G$ & $F$ \\
\hline & $\mathrm{CO}_{2}$ & $V G$ & G & G \\
\hline & $\mathrm{CO}_{3}$ & $M G$ & G & $F$ \\
\hline & $\mathrm{CO}_{4}$ & G & $M G$ & $M G$ \\
\hline & $\mathrm{CO}_{5}$ & $M G$ & G & G \\
\hline \multirow{5}{*}{$C R_{10}$} & $\mathrm{CO}_{1}$ & $F$ & $M G$ & $M G$ \\
\hline & $\mathrm{CO}_{2}$ & G & $V G$ & $V G$ \\
\hline & $\mathrm{CO}_{3}$ & $F$ & $M G$ & $M G$ \\
\hline & $\mathrm{CO}_{4}$ & G & $V G$ & $M G$ \\
\hline & $\mathrm{CO}_{5}$ & $M G$ & $F$ & $G$ \\
\hline
\end{tabular}


Table 2. Cont.

\begin{tabular}{|c|c|c|c|c|}
\hline \multirow{2}{*}{ Criteria } & \multirow{2}{*}{ Contractors } & \multicolumn{3}{|c|}{ Decision Makers } \\
\hline & & $D M_{1}$ & $D M_{2}$ & $\mathrm{DM}_{3}$ \\
\hline \multirow{5}{*}{$C R_{11}$} & $\mathrm{CO}_{1}$ & $M G$ & $F$ & $F$ \\
\hline & $\mathrm{CO}_{2}$ & $V G$ & $G$ & $G$ \\
\hline & $\mathrm{CO}_{3}$ & $M G$ & $F$ & $G$ \\
\hline & $\mathrm{CO}_{4}$ & $G$ & $V G$ & $M G$ \\
\hline & $\mathrm{CO}_{5}$ & $M G$ & $F$ & $G$ \\
\hline \multirow{5}{*}{$C R_{12}$} & $\mathrm{CO}_{1}$ & $F$ & $M P$ & $M P$ \\
\hline & $\mathrm{CO}_{2}$ & $M G$ & $F$ & $F$ \\
\hline & $\mathrm{CO}_{3}$ & $F$ & $M G$ & $M P$ \\
\hline & $\mathrm{CO}_{4}$ & $F$ & $M P$ & $M G$ \\
\hline & $\mathrm{CO}_{5}$ & $M G$ & $G$ & $F$ \\
\hline \multirow{5}{*}{$C R_{13}$} & $\mathrm{CO}_{1}$ & $M G$ & $G$ & $G$ \\
\hline & $\mathrm{CO}_{2}$ & $G$ & $V G$ & $V G$ \\
\hline & $\mathrm{CO}_{3}$ & $M G$ & $F$ & $G$ \\
\hline & $\mathrm{CO}_{4}$ & $G$ & $V G$ & $V G$ \\
\hline & $\mathrm{CO}_{5}$ & G & $M G$ & $V G$ \\
\hline \multirow{5}{*}{$C R_{14}$} & $\mathrm{CO}_{1}$ & $M P$ & $P$ & $F$ \\
\hline & $\mathrm{CO}_{2}$ & $F$ & $M G$ & $M P$ \\
\hline & $\mathrm{CO}_{3}$ & $M P$ & $F$ & $P$ \\
\hline & $\mathrm{CO}_{4}$ & $F$ & $M P$ & $M P$ \\
\hline & $\mathrm{CO}_{5}$ & $F$ & $M G$ & $M P$ \\
\hline \multirow{5}{*}{$C R_{15}$} & $\mathrm{CO}_{1}$ & $M P$ & $F$ & $P$ \\
\hline & $\mathrm{CO}_{2}$ & $F$ & $M G$ & $M P$ \\
\hline & $\mathrm{CO}_{3}$ & $F$ & $M P$ & $M P$ \\
\hline & $\mathrm{CO}_{4}$ & $F$ & $M P$ & $M P$ \\
\hline & $\mathrm{CO}_{5}$ & $F$ & $M G$ & $M G$ \\
\hline \multirow{5}{*}{$C R_{16}$} & $\mathrm{CO}_{1}$ & $F$ & $M P$ & $M P$ \\
\hline & $\mathrm{CO}_{2}$ & $M G$ & $F$ & $G$ \\
\hline & $\mathrm{CO}_{3}$ & $F$ & $M P$ & $M G$ \\
\hline & $\mathrm{CO}_{4}$ & $M G$ & $F$ & $F$ \\
\hline & $\mathrm{CO}_{5}$ & $F$ & $M P$ & $M P$ \\
\hline \multirow{5}{*}{$C R_{17}$} & $\mathrm{CO}_{1}$ & $F$ & $M G$ & $M G$ \\
\hline & $\mathrm{CO}_{2}$ & $M G$ & $F$ & $F$ \\
\hline & $\mathrm{CO}_{3}$ & $M G$ & $G$ & $F$ \\
\hline & $\mathrm{CO}_{4}$ & $M G$ & G & G \\
\hline & $\mathrm{CO}_{5}$ & $F$ & $M G$ & $M G$ \\
\hline \multirow{5}{*}{$C R_{18}$} & $\mathrm{CO}_{1}$ & $M G$ & G & $G$ \\
\hline & $\mathrm{CO}_{2}$ & $V G$ & $V G$ & G \\
\hline & $\mathrm{CO}_{3}$ & G & $M G$ & $V G$ \\
\hline & $\mathrm{CO}_{4}$ & $G$ & $V G$ & $M G$ \\
\hline & $\mathrm{CO}_{5}$ & $M G$ & G & $F$ \\
\hline \multirow{5}{*}{$C R_{19}$} & $\mathrm{CO}_{1}$ & $F$ & $M P$ & $M P$ \\
\hline & $\mathrm{CO}_{2}$ & $G$ & $V G$ & $V G$ \\
\hline & $\mathrm{CO}_{3}$ & $M G$ & $F$ & $G$ \\
\hline & $\mathrm{CO}_{4}$ & $G$ & $M G$ & $V G$ \\
\hline & $\mathrm{CO}_{5}$ & $M G$ & $F$ & $F$ \\
\hline \multirow{5}{*}{$C R_{20}$} & $\mathrm{CO}_{1}$ & $M G$ & $F$ & G \\
\hline & $\mathrm{CO}_{2}$ & $G$ & $V G$ & $M G$ \\
\hline & $\mathrm{CO}_{3}$ & $M G$ & G & $F$ \\
\hline & $\mathrm{CO}_{4}$ & $G$ & $V G$ & $M G$ \\
\hline & $\mathrm{CO}_{5}$ & G & $V G$ & $M G$ \\
\hline
\end{tabular}

Table 1 Linguistic variables for performance ratings. 
The weights of each DM are computed and presented by Equations (15) and (16) and then by Equations (17) and (18), the aggregated IFS decision matrix constructs by the DMs (steps 4 and 5), reported in Table 3.

Table 3. Aggregated IFS decision matrix.

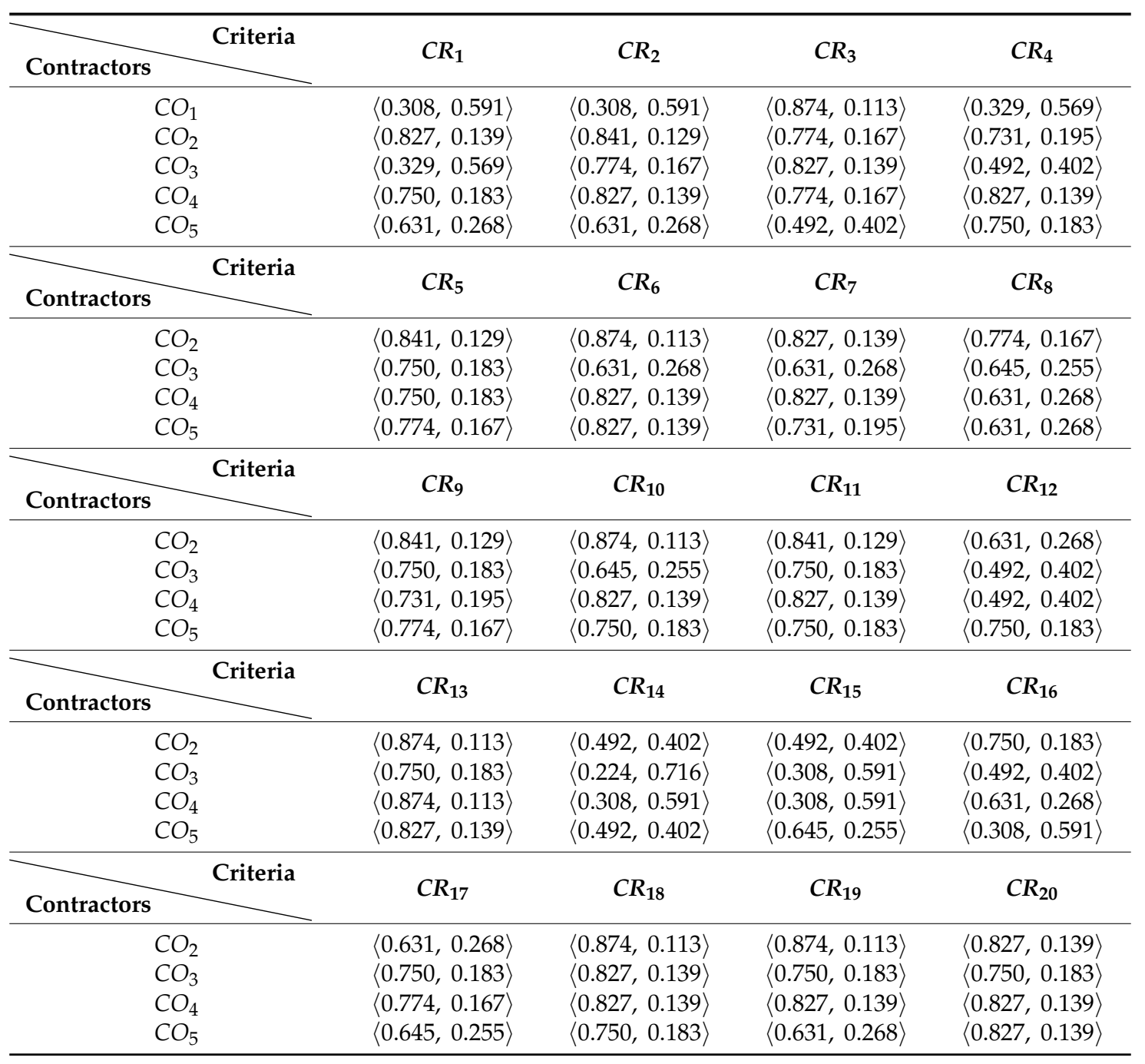

Twenty criteria' weights are established with Equations (19) and (20) and are given in Table 4 (step 6).

Table 4. Aggregated IFS decision matrix by DMs' opinions.

\begin{tabular}{cccccc}
\hline Criteria & $C R_{\mathbf{1}}$ & $C R_{\mathbf{2}}$ & $C R_{\mathbf{3}}$ & $C R_{\mathbf{4}}$ & $C R_{\mathbf{5}}$ \\
Weights & 0.038 & 0.055 & 0.063 & 0.041 & 0.058 \\
\hline Criteria & $C R_{\mathbf{6}}$ & $C R_{\mathbf{7}}$ & $C R_{\mathbf{8}}$ & $C R_{\mathbf{9}}$ & $C R_{\mathbf{1 0}}$ \\
Weights & 0.059 & 0.061 & 0.028 & 0.064 & 0.059 \\
\hline Criteria & $C R_{\mathbf{1 1}}$ & $C R_{\mathbf{1 2}}$ & $C R_{\mathbf{1 3}}$ & $C R_{\mathbf{1 4}}$ & $C R_{\mathbf{1 5}}$ \\
Weights & 0.062 & 0.020 & 0.082 & 0.021 & 0.020 \\
\hline Criteria & $C R_{\mathbf{1 6}}$ & $C R_{\mathbf{1 7}}$ & $C R_{\mathbf{1 8}}$ & $C R_{\mathbf{1 9}}$ & $C R_{\mathbf{2 0}}$ \\
Weights & 0.022 & 0.040 & 0.078 & 0.056 & 0.073 \\
\hline
\end{tabular}


The CS and DS could be identified (step 7). The relative weights of DMs also are reported as:

$$
W^{\prime}=\left[w_{C^{1}}, w_{C^{2}}, w_{C^{3}}, w_{D^{1}}, w_{D^{2}}, w_{D^{3}}\right]=\left[1, \frac{2}{3}, \frac{1}{3}, 1, \frac{2}{3}, \frac{1}{3}\right],
$$

The CS can be:

$C_{k l}^{1}=\left[\begin{array}{ccccc}- & 3,17 & 3,7,13 & 3,9 & 3,7,18 \\ 1,2,4,5,6,7,8,9,10,11, & - & 1,2,4,5,6,7,8,9,10,11, & 1,2,5,6,8,9,10, & 1,2,3,5,6,7,8,9,10, \\ 12,13,16,18,19,20 & - & 12,13,16,18,19,20 & 11,12,16,18,19 & 11,13,16,18,19 \\ 2,5,6,8,11,17,18,19 & 3,17 & - & 3,8,9 & 2,3,8,17,18,19 \\ 1,2,4,5,6,7,8,10,11, & 4,17 & 1,2,4,6,7,10,11 & - & 1,2,3,4,7,10,11 \\ 13,16,17,18,19,20 & & 13,16,17,19,20 & 13,16,17,18,19 \\ 1,2,4,5,6,8,9,10, & 4,12,15,17 & 1,4,5,6,7,9,10, & 5,9,12,15 & - \\ 11,12,13,19,20 & & 12,13,15,20 & \end{array}\right]$

The midrange CS can be:

$$
C_{k l}^{2}=\left[\begin{array}{ccccc}
- & - & - & - & - \\
14,15 & - & 14,15 & 14,15 & \\
1,4,12,15,16 & - & - & - & 16 \\
12,14,15 & - & 14 & - & \\
14,15 & - & 14 & 14 & -
\end{array}\right]
$$

The weak CS can be:

$$
C_{k l}^{3}=\left[\begin{array}{ccccc}
- & - & 9,10,14,20 & - & 16,17 \\
- & - & - & 3,7,13,20 & 14,20 \\
9,10,14,20 & - & - & 5,12,15 & 11 \\
- & 3,7,13,20 & 5,12,15,18 & - & 6,8,20 \\
16,17 & 14,20 & 11 & 6,8,20 & -
\end{array}\right]
$$

The DS can be:

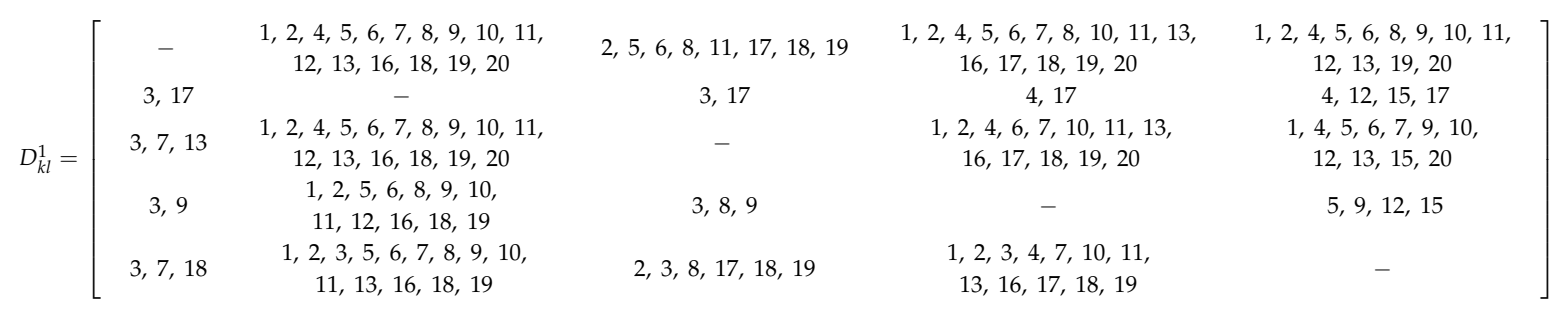

The midrange DS can be:

$$
D_{k l}^{2}=\left[\begin{array}{ccccc}
- & 14,15 & 1,4,12,15,16 & 12,14,15 & 14,15 \\
- & - & - & - & - \\
- & 14,15 & - & 14 & 14 \\
- & 14,15 & - & - & 14 \\
- & - & 16 & - & -
\end{array}\right]
$$

The weak DS can be:

$$
D_{k l}^{3}=\left[\begin{array}{ccccc}
- & - & - & - & - \\
- & - & - & - & - \\
- & - & - & - & - \\
- & - & - & - & - \\
- & - & - & - & -
\end{array}\right]
$$


Then, matrixes of the concordance and discordance can be formed (steps 8 and 9). The respective results can be as:

$$
\begin{aligned}
\Phi & =\left[\begin{array}{ccccc}
- & 0.241 & 1.069 & 0.241 & 0.694 \\
3.711 & - & 3.711 & 3.322 & 2.921 \\
2.922 & 0.241 & - & 1.058 & 1.100 \\
3.614 & 0.827 & 3.332 & - & 2.636 \\
3.401 & 1.503 & 2.934 & 1.631 & -
\end{array}\right], \\
\mathrm{E} & =\left[\begin{array}{ccccc}
- & 1.000 & 1.000 & 1.000 & 0.963 \\
0.165 & - & 0.226 & 0.681 & 0.352 \\
0.285 & 1.000 & - & 1.000 & 1.000 \\
0.178 & 0.731 & 0.115 & - & 1.000 \\
0.780 & 1.000 & 0.909 & 0.960 & -
\end{array}\right]
\end{aligned}
$$

Consequently, matrixes of the CD and DD are constructed (steps 10 and 11). The respective results are as follows:

$$
\Psi=\left[\begin{array}{ccccc}
- & 0.250 & 0.369 & 0.250 & 0.315 \\
0.750 & - & 0.750 & 0.694 & 0.636 \\
0.636 & 0.250 & - & 0.368 & 0.374 \\
0.736 & 0.334 & 0.695 & - & 0.595 \\
0.705 & 0.432 & 0.638 & 0.450 & -
\end{array}\right]
$$

and

$$
\Omega=\left[\begin{array}{ccccc}
- & 0.750 & 0.750 & 0.750 & 0.729 \\
0.278 & - & 0.313 & 0.570 & 0.384 \\
0.346 & 0.750 & - & 0.750 & 0.750 \\
0.285 & 0.598 & 0.250 & - & 0.750 \\
0.626 & 0.750 & 0.698 & 0.727 & -
\end{array}\right]
$$

$\mathcal{I}_{i}, \mathcal{R}_{i}, \mathcal{I}_{i}^{\prime}$ and $\mathcal{R}_{i}^{\prime}$ values are determined (step 12).

$$
\mathcal{I}=\left[\begin{array}{l}
0.296 \\
0.708 \\
0.407 \\
0.590 \\
0.556
\end{array}\right], \mathcal{R}=\left[\begin{array}{l}
0.369 \\
0.750 \\
0.636 \\
0.736 \\
0.705
\end{array}\right], \mathcal{I}^{\prime}=\left[\begin{array}{l}
0.745 \\
0.386 \\
0.390 \\
0.471 \\
0.700
\end{array}\right], \text { and } \mathcal{R}^{\prime}=\left[\begin{array}{c}
0.750 \\
0.570 \\
0.750 \\
0.750 \\
0.750
\end{array}\right]
$$

Then, the values of indices $\delta_{i}$ and $\varrho_{i}$ are computed (step 13).

$$
\delta=\left[\begin{array}{l}
0.000 \\
1.000 \\
0.479 \\
0.812 \\
0.736
\end{array}\right], \text { and } \varrho=\left[\begin{array}{l}
0.000 \\
1.000 \\
0.831 \\
0.562 \\
0.919
\end{array}\right]
$$

Finally, the final value of evaluation index $\left(Q_{i}\right)$ s calculated (step 14) as given in Table 5. The optimal ranking order is as $\mathrm{CO}_{2}>\mathrm{CO}_{4}>\mathrm{CO}_{5}>\mathrm{CO}_{3}>\mathrm{CO}_{1}$ and the best contractors could be the $\mathrm{CO}_{2}$. In addition, the final value of evaluation index $Q_{i}$ for appraising alternatives has been taken in comparison with the fuzzy VIKOR method by the previous study [58] in Table 5 . The results demonstrate that the same ranking results on the CSP are obtained. 
Table 5. Final value of $Q_{i}$ for ranking order of alternatives.

\begin{tabular}{cccc}
\hline Contractors & $Q_{\boldsymbol{i}}$ & $\begin{array}{c}\text { Final Ranking } \\
\text { (Proposed Model) }\end{array}$ & $\begin{array}{c}\text { Final Ranking } \\
\text { (Fuzzy VIKOR by [58]) }\end{array}$ \\
\hline $\mathrm{CO}_{1}$ & 0.000 & 5 & 5 \\
$\mathrm{CO}_{2}$ & 1.000 & 1 & 1 \\
$\mathrm{CO}_{3}$ & 0.369 & 4 & 4 \\
$\mathrm{CO}_{4}$ & 0.599 & 2 & 2 \\
$\mathrm{CO}_{5}$ & 0.443 & 3 & 3 \\
\hline
\end{tabular}

The computational results are given in Table 5; the proposed model (via the GRA, Entropy, IFSs, ELECTRE and new compromise ranking index) versus the modified VIKOR method (via conventional fuzzy sets) by the previous study [58] is compared. Both models can handle complex CSPs with uncertain conditions; however, some main merits of the presented group decision model are provided as below:

- Firstly, this study takes account of key advantages of IFSs and GRA concurrently to handle the uncertain information via the group decision process and to involve more flexibility to illustrate the imprecise and vague data of the several experience DMs.

- Secondly, a new ranking method based on the compromise solution within a new version of classical ELECTRE approach is developed to distinguish potential candidates of the complex CSP as a reasonable way of the optimal ranking, and to introduce stable decisions in the construction industry with uncertain conditions.

\subsection{Sensitivity Analysis}

A sensitivity analysis is represented on each identification coefficient value $\rho$. The computational results can be represented in Table 6 and illustrated in Figure 2. According to Table 6 , the final ranking orders of contractors with the changes of $\rho$ value $(\rho=0.1$ to $\rho=1)$ are the same.

Table 6. Sensitivity analysis on each identification coefficient value.

\begin{tabular}{|c|c|c|c|c|c|c|}
\hline \multirow{2}{*}{$\rho$ Value } & & \multicolumn{5}{|c|}{ Contractors } \\
\hline & & $\mathrm{CO}_{1}$ & $\mathrm{CO}_{2}$ & $\mathrm{CO}_{3}$ & $\mathrm{CO}_{4}$ & $\mathrm{CO}_{5}$ \\
\hline \multirow{2}{*}{$\rho=0.1$} & $Q_{i}$ & 0.000 & 1.000 & 0.377 & 0.618 & 0.441 \\
\hline & Preference order ranking & 5 & 1 & 4 & 2 & 3 \\
\hline \multirow{2}{*}{$\rho=0.2$} & $Q i$ & 0.000 & 1.000 & 0.374 & 0.611 & 0.442 \\
\hline & Preference order ranking & 5 & 1 & 4 & 2 & 3 \\
\hline \multirow{2}{*}{$\rho=0.3$} & $Q i$ & 0.000 & 1.000 & 0.372 & 0.606 & 0.442 \\
\hline & Preference order ranking & 5 & 1 & 4 & 2 & 3 \\
\hline \multirow{2}{*}{$\rho=0.4$} & $Q i$ & 0.000 & 1.000 & 0.370 & 0.602 & 0.443 \\
\hline & Preference order ranking & 5 & 1 & 4 & 2 & 3 \\
\hline \multirow{2}{*}{$\rho=0.5$} & $Q i$ & 0.000 & 1.000 & 0.369 & 0.599 & 0.443 \\
\hline & Preference order ranking & 5 & 1 & 4 & 2 & 3 \\
\hline \multirow{2}{*}{$\rho=0.6$} & $Q i$ & 0.000 & 1.000 & 0.368 & 0.597 & 0.444 \\
\hline & Preference order ranking & 5 & 1 & 4 & 2 & 3 \\
\hline \multirow{2}{*}{$\rho=0.7$} & $Q i$ & 0.000 & 1.000 & 0.368 & 0.595 & 0.444 \\
\hline & Preference order ranking & 5 & 1 & 4 & 2 & 3 \\
\hline \multirow{2}{*}{$\rho=0.8$} & $Q i$ & 0.000 & 1.000 & 0.367 & 0.594 & 0.444 \\
\hline & Preference order ranking & 5 & 1 & 4 & 2 & 3 \\
\hline \multirow{2}{*}{$\rho=0.9$} & $Q i$ & 0.000 & 1.000 & 0.366 & 0.592 & 0.444 \\
\hline & Preference order ranking & 5 & 1 & 4 & 2 & 3 \\
\hline \multirow{2}{*}{$\rho=1$} & $Q i$ & 0.000 & 1.000 & 0.366 & 0.591 & 0.445 \\
\hline & Preference order ranking & 5 & 1 & 4 & 2 & 3 \\
\hline
\end{tabular}




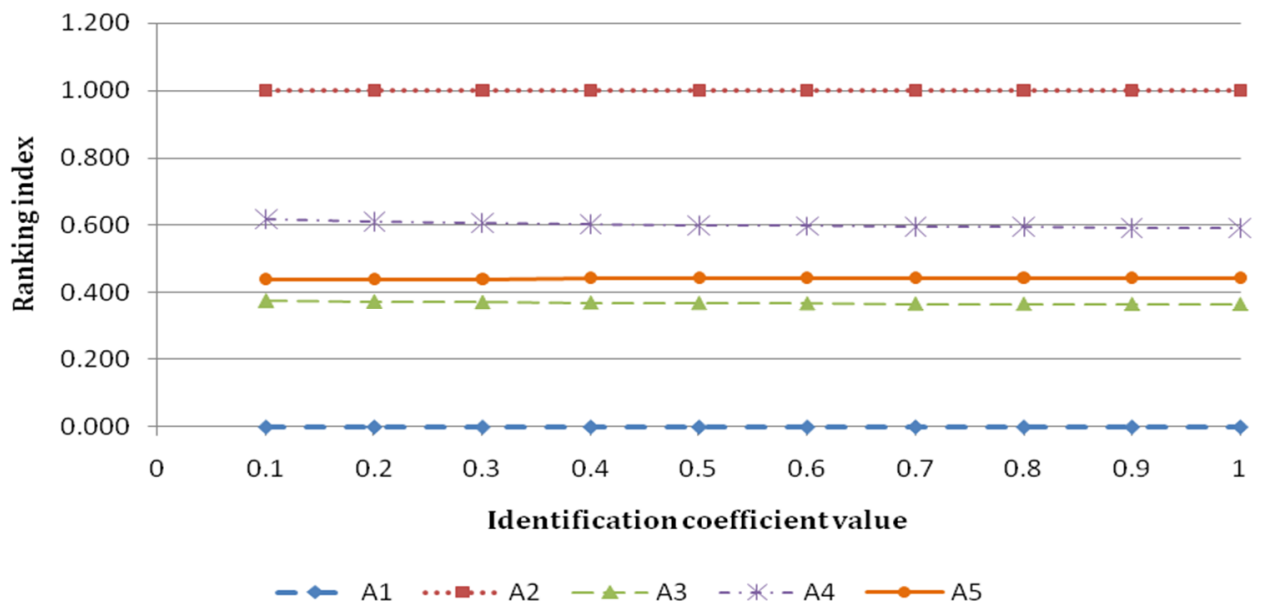

Figure 2. Variation analysis of $Q_{i}$ for the sensitivity analysis.

New group decision model can take account of the gaps between the $Q_{i}$ values of various alternatives appear larger when the coefficient cannot change remarkably, and they have enough stability.

\section{Concluding Remarks and Future Research}

The study introduced a new version of MCGDM model under uncertainty. Major concepts of IFSs theory and GRA were considered in the presented model along with the uncertain ELECTRE and VIKOR methods for selection and assessment problems. For this purpose, linguistic variables denoted by IF-numbers, by regarding the truth-membership and non-truth-membership functions, were utilized to report the importance of each candidate for the complicated problems. Then, a weighting approach was represented for Entropy analysis and IFSs. In addition, a new version of classical ELECTRE method was presented as indicated by the ideas of IFSs and grey theory. Finally, a new ranking index was introduced based on the VIKOR method concept for the appraisement. Furthermore, a case study from the recent literature for construction contractor assessment was indicated to successfully illustrate and validate the proposed model. Comparing with the previous studies, the proposed model assists the DMs or experts with a beneficial way to take fuzzy MCDM complex problems in more generalized methodology because of the way that it applied IFSs rather than conventional fuzzy sets to express the performance ratings of each candidate versus criteria. Although the new decision model provided is demonstrated by a decision problem of the contractor assessment, it is interesting to apply the model in other important management fields, like project selection.

Author Contributions: H.H. and S.M.M. presented the research methodology, performed the development and experiments of this study; E.K.Z. provided extensive advice throughout the study; A.C. and Z.T. assisted with the findings and revised the manuscript. All of the authors have read and approved the final manuscript.

Acknowledgments: The authors are grateful to three anonymous referees for their valuable recommendations that enhanced the quality of the primary version.

Conflicts of Interest: The authors declare no conflict of interest.

\section{References}

1. Hatush, Z.; Skitmore, M. Criteria for contractor selection. Constr. Manag. Econ. 1997, 15, 19-38. [CrossRef]

2. Vahdani, B.; Mousavi, S.M.; Hashemi, H.; Mousakhani, M.; Ebrahimnejad, S. A new hybrid model based on least squares support vector machine for project selection problem in construction industry. Arab. J. Sci. Eng. 2014, 39, 4301-4314. [CrossRef]

3. Liu, P.; Chen, S.M. Multiattribute group decision making based on intuitionistic 2-tuple linguistic information. Inf. Sci. 2018, 430, 599-619. [CrossRef] 
4. Keshavarz Ghorabaee, M.; Zavadskas, E.K.; Olfat, L.; Turskis, Z. Multi-criteria inventory classification using a new method of evaluation based on distance from average solution (EDAS). Informatica 2015, 26, 435-451. [CrossRef]

5. Zavadskas, E.K.; Vilutienè, T.; Turskis, Z.; Tamosaitiene, J. Contractor selection for construction works by applying SAW-G and TOPSIS grey techniques. J. Bus. Econ. Manag. 2010, 11, 34-55. [CrossRef]

6. Zavadskas, E.K.; Turskis, Z.; Antucheviciene, J. Selecting a Contractor by Using a Novel Method for Multiple Attribute Analysis: Weighted Aggregated Sum Product Assessment with Grey Values (WASPAS-G). Stud. Inform. Control 2015, 24, 141-150. [CrossRef]

7. Zagorskas, J.; Zavadskas, E.K.; Turskis, Z.; Burinskienè, M.; Blumberga, A.; Blumberga, D. Thermal insulation alternatives of historic brick buildings in Baltic Sea Region. Energy Build. 2014, 78, 35-42. [CrossRef]

8. Zavadskas, E.K.; Kaklauskas, A.; Turskis, Z.; Kalibatas, D. An approach to multi-attribute assessment of indoor environment before and after refurbishment of dwellings. J. Environ. Eng. Landsc. Manag. 2009, 17, 5-11. [CrossRef]

9. Hashemkhani Zolfani, S.; Zavadskas, E.K.; Turskis, Z. Design of products with both International and Local perspectives based on Yin-Yang balance theory and SWARA method. Econ. Res.-Ekon. Istraž. 2013, 26, 153-166.

10. Gitinavard, H.; Mousavi, S.M.; Vahdani, B. Soft computing-based new interval-valued hesitant fuzzy multi-criteria group assessment method with last aggregation to industrial decision problems. Soft Comput. 2017, 21, 3247-3265. [CrossRef]

11. Ebrahimnejad, S.; Hashemi, H.; Mousavi, S.M.; Vahdani, B. A New Interval-valued Intuitionistic Fuzzy Model to Group Decision Making for the Selection of Outsourcing Providers. J. Econ. Comput. Econ. Cybern. Stud. Res. 2015, 49, 269-290.

12. Khanzadi, M.; Turskis, Z.; Ghodrati Amiri, G.; Chalekaee, A. A model of discrete zero-sum two-person matrix games with grey numbers to solve dispute resolution problems in construction. J. Civ. Eng. Manag. 2017, 23, 824-835. [CrossRef]

13. Wu, M.C.; Chen, T.Y. The ELECTRE multicriteria analysis approach based on Atanassov's intuitionistic fuzzy sets. Expert Syst. Appl. 2011, 38, 12318-12327. [CrossRef]

14. Roy, B. Classement et choix en présence de points de vue multiples. Revue française d'automatique, d'informatique et de recherche opérationnelle. Recherche Opér. 1968, 2, 57-75.

15. Mousavi, M.; Gitinavard, H.; Mousavi, S.M. A soft computing based-modified ELECTRE model for renewable energy policy selection with unknown information. Renew. Sustain. Energy Rev. 2017, 68, 774-787. [CrossRef]

16. Yu, X.; Zhang, S.; Liao, X.; Qi, X. ELECTRE methods in prioritized MCDM environment. Inf. Sci. 2018, 424, 301-316. [CrossRef]

17. Hashemi, S.S.; Hajiagha, S.H.R.; Zavadskas, E.K.; Mahdiraji, H.A. Multicriteria group decision making with ELECTRE III method based on interval-valued intuitionistic fuzzy information. Appl. Math. Model. 2016, 40, 1554-1564. [CrossRef]

18. Azadnia, A.H.; Ghadimi, P.; Saman, M.Z.M.; Wong, K.Y.; Sharif, S. Supplier selection: A hybrid approach using ELECTRE and fuzzy clustering. In International Conference on Informatics Engineering and Information Science; Springer: Berlin/Heidelberg, Germany, 2011; pp. 663-676.

19. Sevkli, M. An application of the fuzzy ELECTRE method for supplier selection. Int. J. Prod. Res. 2010, 48, 3393-3405. [CrossRef]

20. Teixeira de Almeida, A. Multicriteria decision model for outsourcing contracts selection based on utility function and ELECTRE method. Comput. Oper. Res. 2007, 34, 3569-3574. [CrossRef]

21. Montazer, G.A.; Saremi, H.Q.; Ramezani, M. Design a new mixed expert decision aiding system using fuzzy ELECTRE III method for vendor selection. Expert Syst. Appl. 2009, 36, 10837-10847. [CrossRef]

22. Marzouk, M. An application of ELECTRE III to contractor selection. In Construction Research Congress 2010: Innovation for Reshaping Construction Practice; Ruwanpura, J., Mohamed, Y., Lee, S.H., Eds.; American Society of Civil Engineers: Reston, VA, USA, 2010; pp. 1316-1324.

23. You, X.; Chen, T.; Yang, Q. Approach to multi-criteria group decision-making problems based on the best-worst-method and electre method. Symmetry 2016, 8, 95. [CrossRef]

24. Zavadskas, E.K.; Vilutienè, T.; Turskis, Z.; Šaparauskas, J. Multi-criteria analysis of Projects' performance in construction. Arch. Civ. Mech. Eng. 2014, 14, 114-121. [CrossRef] 
25. Hashemi, H.; Mousavi, S.M.; Tavakkoli-Moghaddam, R.; Gholipour, Y. Compromise ranking approach with bootstrap confidence intervals for risk assessment in port management projects. J. Manag. Eng. (ASCE) 2013, 29, 334-344. [CrossRef]

26. Liang, W.; Zhao, G.; Wu, H. Evaluating investment risks of metallic mines using an extended TOPSIS method with linguistic neutrosophic numbers. Symmetry 2017, 9, 149. [CrossRef]

27. Hashemi, H.; Bazargan, J.; Mousavi, S.M.; Vahdani, B. An extended compromise ratio model with an application to reservoir flood control operation under an interval-valued intuitionistic fuzzy environment. Appl. Math. Model. 2014, 38, 3495-3511. [CrossRef]

28. Nie, R.X.; Wang, J.Q.; Zhang, H.Y. Solving solar-wind power station location problem using an extended weighted aggregated sum product assessment (WASPAS) technique with interval neutrosophic sets. Symmetry 2017, 9, 106. [CrossRef]

29. Zavadskas, E.K.; Antucheviciene, J.; Hajiagha, S.H.R.; Hashemi, S.S. Extension of weighted aggregated sum product assessment with interval-valued intuitionistic fuzzy numbers (WASPAS-IVIF). Appl. Soft Comput. 2014, 24, 1013-1021. [CrossRef]

30. Luo, S.Z.; Cheng, P.F.; Wang, J.Q.; Huang, Y.J. Selecting project delivery systems based on simplified neutrosophic linguistic preference relations. Symmetry 2017, 9, 151. [CrossRef]

31. Atanassov, K.T. Intuitionistic fuzzy sets. Fuzzy Sets Syst. 1986, 20, 87-96. [CrossRef]

32. $\mathrm{Xu}, \mathrm{Z}$. Intuitionistic preference relations and their application in group decision making. Inf. Sci. 2007, 177, 2363-2379. [CrossRef]

33. Chen, R.Y. A problem-solving approach to product design using decision tree induction based on intuitionistic fuzzy. Eur. J. Oper. Res. 2009, 196, 266-272. [CrossRef]

34. Ye, J. Fuzzy decision-making method based on the weighted correlation coefficient under intuitionistic fuzzy environment. Eur. J. Oper. Res. 2010, 205, 202-204. [CrossRef]

35. Li, D.F.; Chen, G.H.; Huang, Z.G. Linear programming method for multi-attribute group decision making using IF sets. Inf. Sci. 2010, 180, 1591-1609. [CrossRef]

36. Liu, P. Multiple attribute decision-making methods based on normal intuitionistic fuzzy interaction aggregation operators. Symmetry 2017, 9, 261. [CrossRef]

37. Fouladgar, M.M.; Yazdani-Chamzini, A.; Zavadskas, E.K.; Yakhchali, S.H.; Ghasempourabadi, M.H. Project portfolio selection using fuzzy AHP and VIKOR techniques. Transform. Bus. Econ. 2012, 11, 213-231.

38. Hashemi, H.; Bazargan, J.; Mousavi, S.M. A Compromise Ratio Method with an Application to Water Resources Management: An Intuitionistic Fuzzy Set. Water Res. Manag. 2013, 27, 2029-2051. [CrossRef]

39. Zhao, J.; You, X.Y.; Liu, H.C.; Wu, S.M. An extended VIKOR method using intuitionistic fuzzy sets and combination weights for supplier selection. Symmetry 2017, 9, 169. [CrossRef]

40. Hosseinzadeh, F.; Sarpoolaki, H.; Hashemi, H. Precursor Selection for Sol-Gel Synthesis of Titanium Carbide Nanopowders by a New Intuitionistic Fuzzy Multi-Attribute Group Decision-Making Model. Int. J. Appl. Ceram. Technol. 2014, 11, 681-698. [CrossRef]

41. Zavadskas, E.K.; Antucheviciene, J.; Razavi Hajiagha, S.H.; Hashemi, S.S. The interval-valued intuitionistic fuzzy MULTIMOORA method for group decision making in engineering. Math. Probl. Eng. 2015, 560690. [CrossRef]

42. Keshavaraz Ghorabaee, M.K.; Amiri, M.; Sadaghiani, J.S.; Zavadskas, E.K. Multi-Criteria Project Selection Using an Extended VIKOR Method with Interval Type-2 Fuzzy Sets. Int. J. Inf. Technol. Decis. Mak. 2015, 14, 993-1016. [CrossRef]

43. Shu, M.H.; Cheng, C.H.; Chang, J.R. Using intuitionistic fuzzy sets for fault-tree analysis on printed circuit board assembly. Microelectron. Reliab. 2006, 46, 2139-2148. [CrossRef]

44. De, S.K.; Biswas, R.; Roy, A.R. Some operations on intuitionistic fuzzy sets. Fuzzy Sets Syst. 2000, 114, 477-484. [CrossRef]

45. Chen, S.M.; Tan, J.M. Handling multicriteria fuzzy decision-making problems based on vague set theory. Fuzzy Sets Syst. 1994, 67, 163-172. [CrossRef]

46. Hong, D.H.; Choi, C.H. Multicriteria fuzzy decision-making problems based on vague set theory. Fuzzy Sets Syst. 2000, 114, 103-113. [CrossRef]

47. Xu, Z.; Yager, R.R. Some geometric aggregation operators based on intuitionistic fuzzy sets. Int. J. Gen. Syst. 2006, 35, 417-433. [CrossRef] 
48. Szmidt, E.; Kacprzyk, J. Distances between intuitionistic fuzzy sets. Fuzzy Sets Syst. 2000, 114, 505-518. [CrossRef]

49. Shannon, C.E. Communication Theory of Secrecy Systems. Bell Syst. Tech. J. 1949, 28, 656-715. [CrossRef]

50. Ye, J. Multiple attribute group decision-making methods with completely unknown weights in intuitionistic fuzzy setting and interval-valued intuitionistic fuzzy setting. Group Decis. Negot. 2013, 22, 173-188. [CrossRef]

51. Celik, E.; Bilisik, O.N.; Erdogan, M.; Gumus, A.T.; Baracli, H. An integrated novel interval type-2 fuzzy MCDM method to improve customer satisfaction in public transportation for Istanbul. Transp. Res. Part E Logist. Transp. Rev. 2013, 58, 28-51. [CrossRef]

52. Chen, W.H. A grey-based approach for distribution network reconfiguration. J. Chin. Inst. Eng. 2005, 28, 795-802. [CrossRef]

53. Kuo, M.S.; Liang, G.S. Combining VIKOR with GRA techniques to evaluate service quality of airports under fuzzy environment. Expert Syst. Appl. 2011, 38, 1304-1312. [CrossRef]

54. Wei, G.W. Gray relational analysis method for intuitionistic fuzzy multiple attribute decision making. Expert Syst. Appl. 2011, 38, 11671-11677. [CrossRef]

55. Zavadskas, E.K.; Turskis, Z.; Volvačiovas, R.; Kildiene, S. Multi-criteria assessment model of technologies. Stud. Inform. Control 2013, 22, 249-258. [CrossRef]

56. Turskis, Z.; Juodagalvienè, B. A novel hybrid multi-criteria decision-making model to assess a stairs shape for dwelling houses. J. Civ. Eng. Manag. 2016, 22, 1078-1087. [CrossRef]

57. Turskis, Z.; Daniūnas, A.; Zavadskas, E.K.; Medzvieckas, J. Multicriteria evaluation of building foundation alternatives. Comput.-Aided Civ. Infrastruct. Eng. 2016, 31, 717-729. [CrossRef]

58. Vahdani, B.; Mousavi, S.M.; Hashemi, H.; Mousakhani, M.; Tavakkoli-Moghaddam, R. A new compromise solution method for fuzzy group decision-making problems with an application to the contractor selection. Eng. Appl. Artif. Intell. 2013, 26, 779-788. [CrossRef]

(C) 2018 by the authors. Licensee MDPI, Basel, Switzerland. This article is an open access article distributed under the terms and conditions of the Creative Commons Attribution (CC BY) license (http:// creativecommons.org/licenses/by/4.0/). 